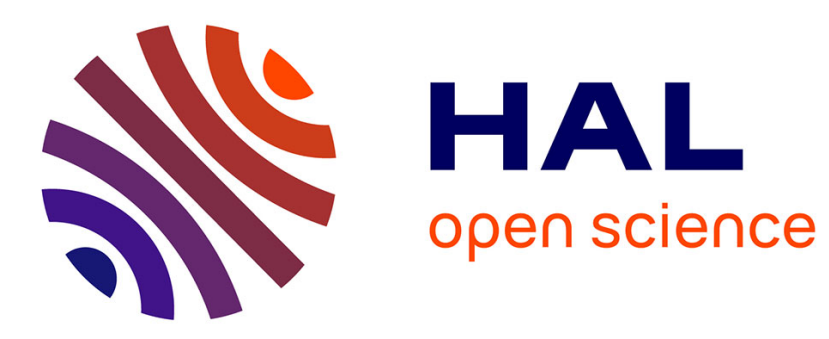

\title{
Endogenous Growth and European Fiscal Rules
}

Oscar Joao Afonso, Rui Henrique Alves

\section{To cite this version:}

Oscar Joao Afonso, Rui Henrique Alves. Endogenous Growth and European Fiscal Rules. Applied Economics, 2009, 41 (07), pp.849-858. 10.1080/00036840701604503 . hal-00582207

\section{HAL Id: hal-00582207 https://hal.science/hal-00582207}

Submitted on 1 Apr 2011

HAL is a multi-disciplinary open access archive for the deposit and dissemination of scientific research documents, whether they are published or not. The documents may come from teaching and research institutions in France or abroad, or from public or private research centers.
L'archive ouverte pluridisciplinaire HAL, est destinée au dépôt et à la diffusion de documents scientifiques de niveau recherche, publiés ou non, émanant des établissements d'enseignement et de recherche français ou étrangers, des laboratoires publics ou privés. 


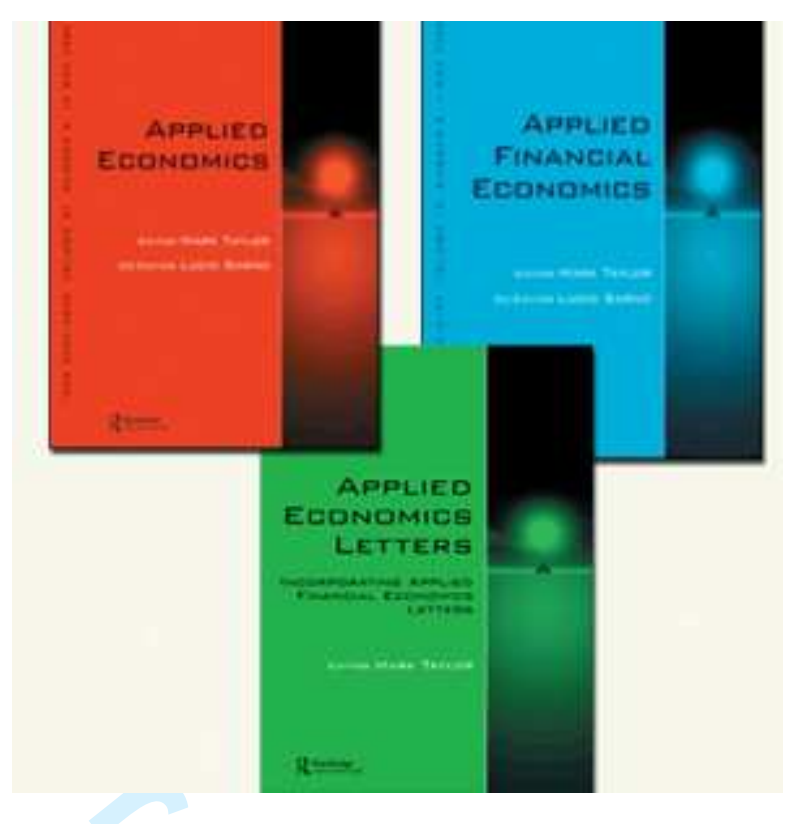

\section{Endogenous Growth and European Fiscal Rules}

\begin{tabular}{|r|l|}
\hline Journal: & Applied Economics \\
\hline Manuscript ID: & APE-06-0801.R1 \\
\hline Journal Selection: & Applied Economics \\
\hline Date Submitted by the \\
Author: & $17-J u l-2007$ \\
\hline Complete List of Authors: & $\begin{array}{l}\text { Afonso, Oscar; Universidade do Porto, Faculdade de Economia } \\
\text { Alves, Rui; Universidade do Porto, Faculdade de Economia }\end{array}$ \\
\hline JEL Code: & $\begin{array}{l}\text { O31 - Innovation and Invention: Processes and Incentives < O3 - } \\
\text { Technological Change|Research and Development }<\text { O - Economic } \\
\text { Development, Technological Change, and Growth, O38 - } \\
\text { Government Policy < O3 - Technological Change|Research and } \\
\text { Development < O - Economic Development, Technological Change, } \\
\text { and Growth, H60 - General < H6 - National Budget, Deficit, and } \\
\text { Debt < H - Public Economics, E62 - Fiscal Policy|Public } \\
\text { Expenditures, Investment, and Finance|Taxation < E6 - Macro } \\
\text { Policy Formation, Macro Public Finance, Macro Policy, etc }<\text { E - } \\
\text { Macroeconomics and Monetary Economics, C61 - Optimization } \\
\text { Techniques|Programming Models|Dynamic Analysis < C6 - } \\
\text { Mathematical Methods and Programming < C - Mathematical and } \\
\text { Quantitative Methods }\end{array}$ \\
\hline Keywords: & \begin{tabular}{l} 
Technological-Knowledge Gap, Monetary Union, SGP, Excessive \\
\hline
\end{tabular} \\
\hline
\end{tabular}




\title{
Endogenous Growth and European Fiscal Rules
}

\author{
Oscar Afonso* and Rui Henrique Alves \\ Faculdade de Economia, Universidade do Porto and CEMPRE ${ }^{\dagger}$
}

First version - December 2006

This version - July 2007

\begin{abstract}
We develop a general equilibrium endogenous growth model of a monetary union between two countries that differ in economic dimension and level of development. By solving transitional dynamics towards the steady state, we examine the impact of fiscal shocks that may lead to excessive deficits. Results suggest that the individual and the whole impact of such deficits depend on which country they occur. In such context, we argue that the small and less developed country should be allowed to temporarily run an excessive deficit, in order to improve economic convergence within the union.
\end{abstract}

Keywords: Technological-Knowledge Gap; Monetary Union; SGP; Excessive Deficits; Numerical Computation.

JEL Classification: O31, O38, H60, E62, C61.

\footnotetext{
* Corresponding author. E-mail address: oafonso@fep.up.pt. Address: Rua Dr. Roberto Frias 4200-464 Porto, Portugal. Fax: +351 225505050. Tel: +351225571100 .

${ }^{\dagger}$ CEMPRE (Centro de Estudos Macroeconómicos e Previsão) is supported by Fundação para a Ciência e a Tecnologia, Portugal.
} 


\section{Introduction}

With the creation of the European Monetary Union (EMU), the framework for the definition and implementation of macroeconomic policies has dramatically changed. Member-Countries have lost their exchange rate and money supply instruments and fiscal policy has been restrained by binding rules aimed at avoiding excessive public deficits.

The need for fiscal discipline was justified by the potential external negative effects that could result from excessive deficits run by any participant in the eurozone. These effects (e.g., De Grauwe, 2005) included a possible increase in the interest rate of the EMU, leading to possible pressures on the European Central Bank (ECB) to implement a more expansionist monetary policy, thus leading to an increase in inflation. Fundamentally, European fiscal rules have been put in place because of the need to keep price stability (e.g., Baldwin and Wyplosz, 2006).

The above-mentioned rules included a maximum ceiling for the deficit to GDP ratio (3\%) and for the public debt to GDP ratio $(60 \%)$ and were consecrated by the Maastricht Treaty (1992). Further, the need for fiscal discipline has been improved by the rules of the Stability and Growth Pact (SGP), which assumed a budgetary equilibrium (or even a small budgetary surplus) as the fundamental goal in terms of the medium-run, in order to preserve some margin for manoeuvre for fiscal policy in the case of a negative shock. The SGP also established concrete sanctions to be applied to countries that maintain excessive deficits and do not comply with Council recommendations (European Council, 1997).

Since the beginning, these rules have been the main object of discussion among academics and politicians with regard to fiscal policy in the eurozone. Positions vary from strong support for the current framework to proposals for important changes in it or even to appeals for a radical change, which could include the federalisation of fiscal policy (Alves and Afonso, 2007). 
Among the arguments put forward in favour of major changes in the original SGP, we find the idea that fiscal rules would differ according to the level of development of the Member-Countries and their economic dimension.

The goal of economic and social cohesion would require higher rates of real GDP in the less developed countries, which in turn would require stronger public intervention and would be compatible with temporary public deficit and debt ratios higher than those proposed in the SGP. Moreover, several authors (e.g., Mills and Quinet, 2001; Brunila, 2002; Creel, 2003) suggested the substitution of current rules by the "golden rule" or the introduction of rules concerning public expenses (and not strictly the public deficit).

In particular, some expenses related to public investment would be excluded from the calculus of the relevant public deficit concerning the application of the " 3 per cent" rule, following the idea, expressed in some literature (e.g., Milbourne et al., 2003) that public investment may help economic growth.

The other argument concerns external spillovers resulting from excessive deficits in one country, as they would only occur or be relevant if such country was big (like Germany), thus affecting financial markets and price stability in a relevant way.

The debate is not yet closed, but it may already have made a relevant contribution to the recent SGP reform (European Council, 2005). The "new" SGP allows for a growing number of circumstances that lead to a non-automatic application of sanctions, namely considering a diversified kind of public expenses that may justify the non-compliance to the " 3 per cent" rule. As far as the present paper is concerned, it is relevant to note that, within that set, expenses regarding R\&D are included.

In order to analyse whether or not such kind of public expenses should be treated differently and whether or not fiscal rules should differ between countries, we consider a standard economic structure in endogenous R\&D-growth theory, for two countries that compose a monetary union. In each country, the production of perfectly competitive final 
goods uses institutions and labour together with a continuum set of country specific quality-adjusted intermediate goods. Intermediate goods, in turn, use designs (resulting from R\&D activities) under monopolistic competition.

The production function, in which the complementarity of inputs, in each country, is coupled with substitutability between countries, is adapted from the horizontal R\&D growth models developed by Acemoglu and Zilibotti (2001) as well as from the vertical R\&D growth model presented by Afonso (2006). As a result of the close relationship between the production of intermediate goods and $R \& D$, this one can be encouraged either by a direct subsidy or through a subsidy to the production of intermediate goods. Some empirical studies show a positive impact of public intervention on R\&D (e.g., Falk, 2006).

These policies have a negative impact on the fiscal budget of each country and that situation may lead to adverse consequences, such as those prevented by the SGP. However, they may reduce the technological-knowledge gap between countries and, through this, increase the competitiveness of the less developed one. In this case, they could be crucial for an increase in the economic convergence within the union and, in particular, for the economic growth performance of the poorer country, thus justifying a differentiation in fiscal rules. This will be the focus of the present work.

By assumption, countries differ in three features: (i) economic dimension, measured by labour endowments; the one with higher active population is called Big, the other one is called Small; (ii) domestic institutions, which are more advanced in the Big-country; (iii) domestic quality indexes measuring technological knowledge, which are higher in the Big-country, as an endogenous consequence of the other two and measuring the level of development of each country.

The paper is structured as follows. Section 2 describes the model. Section 3 determines the equilibrium conditions. Section 4 analyses the effects of a governmental intervention. Finally, section 5 offers some concluding remarks. 


\section{The model}

\subsection{Final-goods sector}

Each final good $n \in[0,1]$ is produced by one of two countries, the Small-country, $S$, and the Big-country, $B$. The former (latter) brings institutions, $A_{S}\left(A_{B}\right)$, and labour, $L_{S}\left(L_{B}\right)$, together with a continuum set of $S(B)$ specific quality-adjusted intermediate goods, indexed by $j \in[0, J(j \in] J, 1])$. The output of $n, Y_{n}$, at time $t$ is,

$$
Y_{n}(t)=\left[\int_{0}^{J}\left(q^{k(j, t)} x_{n}(k, j, t)\right)^{1-\alpha} d j\right]\left[(1-n) A_{S}^{1 / \alpha} L_{S, n}\right]^{\alpha}+\left[\int_{J}^{1}\left(q^{k(j, t)} x_{n}(k, j, t)\right)^{1-\alpha} d j\right]\left[n A_{B}^{1 / \alpha} L_{B, n}\right]^{\alpha}
$$

The integrals denote the contribution of intermediate goods to production. In the Schumpeterian tradition, the quantity of each $j, x_{n}$, used in the production of the final good $n$ is quality-adjusted; i.e., the quality upgrade is $q>1$, and $k$ is the top-quality rung at time $t$. The term $1-\alpha$ is the aggregate intermediate-goods input share.

The second and fourth terms on the right-hand side of (1) can be interpreted as representing the role of the labour to production, respectively, in $S$ and in $B$. These terms include the labour levels of each country, where, by assumption, $L_{B}>L_{S}$. The term $A$ is an exogenous variable representing the level of productivity, dependent on country's institutions. As B's institutions are, by hypothesis, more advanced, we consider $A_{B}>A_{S}>1$, which means that an absolute productivity advantage of $L_{B}$ over $L_{S}$ is accounted. A relative productivity advantage of either type is captured by (1-n) and $n$, which implies that $L_{S}\left(L_{B}\right)$ is relatively more productive in final goods indexed by smaller (larger) $n \mathrm{~s}$. The parameter $\alpha \in] 0,1[$ represents the labour input share.

Finally, as we will see below, at each time $t$ there is a competitive equilibrium threshold final good $\bar{n}$, where the switch from one country to the other becomes advantageous. An increase in $\bar{n}$ would mean a larger space for production in country $S$, thus appearing as a measure of its relative competitiveness. 
Due to zero profit equilibrium by producers of $n \in[0,1]$, the demand for the topquality of $j$ by the producer of $n$ is

$$
x_{n}(k, j, t)=\left[\frac{p_{n}(t)(1-\alpha)}{p(j, t)}\right]^{1 / \alpha} q^{k(j, t)[(1-\alpha) / \alpha]}\left\{\begin{array}{c}
(1-n) A_{S}^{1 / \alpha} L_{S, n}(t), \text { if } 0<j \leq J ; \text { i.e., } n \text { is produced in } S \\
n A_{B}^{1 / \alpha} L_{B, n}(t), \text { if } J<j \leq 1 ; \text { i.e., } n \text { is produced in } B
\end{array} .\right.
$$

where: $p_{n}$ and $p(j)$ are, respectively, the prices of $n$ and $j$. A higher $p_{n}$ increases the marginal revenue product of the factors, encouraging firms to rent more intermediate goods. A higher $L_{S, n}$ or $L_{B, n}$ implies that more labour is used with intermediate goods, raising demand. Finally, a higher $p(j)$ means lower demand, since the demand curve for intermediate goods is downward sloping. Plugging (2) into (1), we have the supply of $n$ :

$$
\begin{gathered}
Y_{n}(t)=\left[\frac{p_{n}(t)(1-\alpha)}{p(j, t)}\right]^{\left(\frac{1-\alpha}{\alpha}\right)}\left[n A_{B}^{1 / \alpha} L_{B, n} Q_{B}(t)+(1-n) A_{S}^{1 / \alpha} L_{S, n} Q_{S}(t)\right], \\
\text { where: } Q_{S}(t)=\int_{0}^{J} q^{k(j, t)[(1-\alpha) / \alpha]} d j \text { and } Q_{B}(t)=\int_{J}^{1} q^{k(j, t)[(1-\alpha) / \alpha]} d j,
\end{gathered}
$$

are aggregate quality indexes, measuring the technological knowledge in the countryspecific range of intermediate goods.

Let us define $G \equiv Q_{B} / Q_{S}$. $G$ accounts for the relative technological-knowledge level of $B$ 's specific intermediate goods, giving a measure of the technological-knowledge gap between countries or, in other words, of the economic development gap. An endogenous relevant result shown later is that $G^{-1}<1$, since $S$ has less labour and worse institutions. This result will allows us to analyse if a country specific governmental intervention may improve $S$ 's situation, thus questioning the existence of a "one size fits all" fiscal rule.

We define the aggregate output of the union, i.e., the composite final good, as:

$$
Y(t) \equiv \int_{0}^{1} p_{n}(t) Y_{n}(t) d n=\exp \left[\int_{0}^{1} \ln p_{n}(t) d n\right] \exp \left[\int_{0}^{1} \ln Y_{n}(t) d n\right]=\exp \left[\int_{0}^{1} \ln Y_{n}(t) d n\right],
$$

where we normalise its price at each time $t$ to one (numeraire). Resources of the union, $Y$, that are not consumed, $C$, are used in the production of intermediate goods, $X$, and in the R\&D sector, $R$; i.e., $Y=X+R+C$. 


\subsection{Intermediate-goods sector}

Since $Y$ is the input in the production of $j \in[0,1]$ and final goods are produced in perfect competition, the marginal cost of production of $j \in[0,1]$ is 1 , regardless of the country. Assuming that the government of each country can subsidise the production of $j$ by paying an ad-valorem fraction, $z_{x}$ (more specifically, $z_{x, S}$ in $S$ and $z_{x, B}$ in $B$ ), of each firm's cost, the after-subsidy marginal cost of producing $j$ is $\left(1-z_{x}\right)$; i.e., $\left(1-z_{x, S}\right)$ in $S$ and $\left(1-z_{x, B}\right)$ in $B$.

Following Romer (1990), $j$ embodies a costly design (created in the R\&D sector), which is recovered if profits at each date are positive for a certain time in future. This is assured by a patent law, which protects each leader firm's monopoly, while at the same time, almost without costs, spreading acquired technological knowledge to other firms.

The profit-maximisation price of the monopolistic firms yields the constant over $t$, across $j$ and for all $k$ mark-up $p(k, j, t)=p=\left(1-z_{x}\right) /(1-\alpha)$, which, with $z_{x}<\alpha$, is in fact a mark-up over 1 . Without any change in government intervention, this mark-up is stable over $t$, across $j$ and for all $k$. This symmetry is thus dictated by the way in which each $j$ enters (1) and by the fact that all intermediate good producers use the same input.

Since the leader firm is the only one legally allowed to produce the top-quality, it will use pricing to wipe out sales of lower quality. Depending on whether $q(1-\alpha)$ is greater or lesser than the marginal cost, it will respectively use the monopoly pricing $p=\left(1-z_{x}\right) /(1-\alpha)$ or the limit pricing $p=q\left(1-z_{x}\right)$ to capture all the market. As in Grossman and Helpman (1991, Ch. 4), it is assumed that limit pricing strategy is used by all firms. Since the lowest price that the closest follower can charge without negative profits is $\left(1-z_{x}\right)$, the leader can capture all the market by selling at a price slightly below $q\left(1-z_{x}\right)$, because $q$ represents the quality advantage over the closest follower. 


\subsection{R\&D sector}

The outcomes of R\&D are designs, which improve the quality of intermediate goods and the quality indexes in (4), while creatively destroying the profits from previous advances (e.g., Aghion and Howitt, 1992), as the previous best quality loses that status.

As in Afonso (2006), in $j$ at $t$, a firm engaged in R\&D that uses $y(k, j, t)$ flow of $Y$ is successful in upgrading the next quality, $k(j, t)+1$, with instantaneous probability

$$
I(k, j, t)=y(k, j, t) \cdot \beta q^{k(j, t)} \cdot \zeta^{-1} q^{-\alpha^{-1} k(j, t)}, \text { where: }
$$

(i) the $\mathrm{R} \& \mathrm{D}$ activity is located in $S(B)$ if $0 \leq j \leq J(J<j \leq 1)$; (ii) $\beta q^{k(j, t)}, \beta>0$, is the positive learning effect of accumulated public technological knowledge from past R\&D in $j$ (e.g., Connolly, 2003); (iii) $\zeta^{-1} q^{-\alpha^{-1} k(j, t)}, \zeta>0$, is the adverse effect caused by the increasing complexity of quality improvements in $j$ (e.g., Kortum, 1997). ${ }^{1}$

As mentioned earlier, we will allow each of the governments to subsidise R\&D activities directly, by means of an ad-valorem subsidy $z_{r}$, which can be country-specific (i.e., $z_{r, S}$ in $S$ and $z_{r, B}$ in $B$ ).

\subsection{Consumers}

A time-invariant number of heterogeneous individuals continuously indexed by $a \in[0,1]$ decide the allocation of income, which is partly spent on consumption of the composite final good, and partly lent in return for future interest. For simplicity, we consider an exogenous threshold individual $\bar{a}$, smaller than 0.5 , since $L_{B}=\int_{\bar{a}}^{1} d a>L_{S}=\int_{0}^{\bar{a}} d a$ : individuals $a>\bar{a}$ are located in $B$, whereas individuals $a \leq \bar{a}$ are located in $S$.

The infinite horizon lifetime utility of the individual $a$ is:

$$
U(a, t)=\int_{0}^{\infty}\left[\frac{c(a, t)^{1-\theta}-1}{1-\theta}\right] \exp (-\rho t) d t,
$$

\footnotetext{
${ }^{1}$ As $B$ is more developed, it can instead be considered $\beta_{B} \zeta_{S}>\beta_{S} \zeta_{B}$ (B has a better innovation capacity).
} 
where: (i) $c(a, t)$ is the amount of consumption of the composite final good by the individual $a$, at time $t$; (ii) $\rho>0$ is the homogeneous subjective discount rate; and (iii) $\theta>0$ is the inverse of the inter-temporal elasticity of substitution.

Savings consist of accumulation of financial assets $-K$, with return $r$ - in the form of public debt owned by individuals and in the form of ownership of the firms that produce intermediate goods in monopolistic competition. ${ }^{2}$ Thus, the budget constraint is:

$$
\dot{K}(a, t)+c(a, t)=\left[1-\tau_{K}\right] r(t) K(a, t)+\left\{\begin{array}{l}
{\left[1-\tau_{w, S}\right] w_{S}(a, t), \text { if } a \leq \bar{a}} \\
{\left[1-\tau_{w, B}\right] w_{B}(a, t), \text { if } a>\bar{a}}
\end{array},\right. \text { where: }
$$

(i) $K(a, t)$ is the total asset holdings of individual $a$, with return $r$; (ii) $w(a, t)$ is the wage of individual $a$, at time $t$; (iii) $\tau_{K}$ and $\tau_{w}$ are ad-valorem taxes on assets and wages, respectively, which may be used by the government for fiscal policy purposes (in particular, as a means of financing, at least partially, the costs of the above mentioned subsidies); (iv) $w$ and $\tau_{w}$ may differ between countries, but not $\tau_{K}$; (v) $r$ is the same within the union, as a natural consequence of the monetary union.

Maximising (7) subject to (8) yields the growth rate of consumption, which is independent of the individual and is the standard Euler equation:

$$
\hat{c}(a, t)=\hat{c}(t)=\hat{C}(t)=\frac{1}{\theta}\left[\left(1-\tau_{K}\right) r(t)-\rho\right], \text { where } C(t) \equiv \int_{0}^{1} c(a, t) d a .
$$

\subsection{Government}

The government of each country may intervene by imposing taxes on wages and/or on financial assets and by subsidising the production of intermediate goods and/or R\&D activities. If necessary, the government may run a public deficit by issuing public debt sold to individuals. The budget surplus, $B u S$, of $S$ and $B$ is thus given respectively by:

\footnotetext{
${ }^{2}$ The value of these firms, in turn, corresponds to the value of patents in use.
} 
$(1+r(t)) B u S_{S}(t)=\tau_{K} r(t) \int_{0}^{\bar{a}} K(a, t) d a+\tau_{w, S} \int_{0}^{\bar{a}} w(a, t) d a-z_{x, S} X_{S}(t)-z_{r, S} R_{S}(t)-r(t) D_{S}(t)$

$$
(1+r(t)) B u s_{B}(t)=\tau_{K} r(t) \int_{\bar{a}}^{1} K(a, t) d a+\tau_{w, B} \int_{\bar{a}}^{1} w(a, t) d a-z_{x, B} X_{B}(t)-z_{r, B} R_{B}(t)-r(t) D_{B}(t) \cdot
$$

Where: (i) $X_{S}\left(X_{B}\right)$ represents the resources devoted to intermediate goods production in $S(B)$; (ii) $R_{S}\left(R_{B}\right)$ represents the resources devoted to R\&D in $S(B)$; and (iii) $D_{S}\left(D_{B}\right)$ represents the public debt in $S(B)$. The first and second terms on the righthand side represent government tax revenue while the third and fourth terms represent government expenditure on subsidies for intermediate goods and for $\mathrm{R} \& \mathrm{D}$, respectively, and the last term relates to interest paid on public debt.

We will be particularly interested in the effects of higher levels of subsidies in the less developed country, regarding an eventual convergence towards the level of development of the other country.

\section{Equilibrium}

The dynamic general equilibrium resulting from optimal decentralised behaviour can be described by the paths of $Q_{S}$ and $Q_{B}$ towards the steady state.

\subsection{Equilibrium for given technological knowledge}

The competitive advantage of either country on the production of the $n^{\text {th }}$ final good relies on the relative productivity related with the quality of national institutions, $\left(A_{B} / A_{S}\right)^{1 / \alpha}$ and on the price of the country-specific labour, as well as on the relative productivity and prices of the intermediate goods, because of complementarity in production.

The prices of labour depend on the quantities, $L_{B}$ and $L_{S}$. In relative terms, the productivity-adjusted quantity of $L_{B}$ in production is $A_{B}^{\alpha^{-1}} A_{S}^{-\alpha^{-1}} L_{B} L_{S}^{-1}$. As for the productivity and prices of intermediate goods, they depend on complementarity with either labour, on the technological knowledge in the country-specific range of intermediate goods and on the mark-up. These determinants are summed up in $Q_{B}$ and $Q_{S}$ in (4). 
The endogenous threshold final good $\bar{n}$ follows from equilibrium in the inputs markets and relies on the determinants of the competitive advantage in final goods. ${ }^{3}$

$$
\bar{n}(t)=\left\{1+\left[G(t) \frac{A_{B}^{\alpha^{-1}} L_{B}}{A_{S}^{\alpha^{-1}} L_{S}}\right]^{\frac{1}{2}}\right\}^{-1}
$$

It can be related to prices noting that it is indifferent to produce $\bar{n}$ in $B$ or $S$. This yields the ratio of index prices of final goods produced in each country,

$$
\frac{p_{B}(t)}{p_{S}(t)}=\left[\frac{\bar{n}(t)}{1-\bar{n}(t)}\right]^{\alpha}, \text { where: }\left\{\begin{array}{l}
p_{S}=p_{n}(1-n)^{\alpha}=\exp (-\alpha) \bar{n}^{-\alpha} \\
p_{B}=p_{n} n^{\alpha}=\exp (-\alpha)(1-\bar{n})^{-\alpha}
\end{array} \text { since } \exp \int_{0}^{1} \ln p_{n} d n=1\right.
$$

Equation (11) shows that a higher economic development gap, $G$, a larger relative supply of labour, $L_{B} / L_{S}$, and/or a higher relative productivity concerning the quality of national institutions, $A_{B} / A_{S}$, results in a higher fraction of final goods produced in $B$, thus in a small $\bar{n}$. By (12), small $\bar{n}$ implies a low relative price of final goods produced by $B$. In this case, the demand for $B$ specific intermediate goods is relatively low, which discourages $\mathrm{R} \& \mathrm{D}$ activities aimed at improving their quality, as we can see below.

The equilibrium aggregate resources devoted to intermediate-goods production, $X=X_{B}+X_{S}$, and the equilibrium aggregate output, $Y=Y_{B}+Y_{S}$, i.e., the composite final good in the union (5), are expressible as a function of the currently given factor levels,

$$
\begin{gathered}
X(t) \equiv \int_{0}^{1} \int_{0}^{1} x_{n}(k, j, t) d j d n=\left[\frac{p_{S}(t) A_{S}(1-\alpha)}{q\left(1-z_{x, S}\right)}\right]^{1 / \alpha} L_{S} Q_{S}(t)+\left[\frac{p_{B}(t) A_{B}(1-\alpha)}{q\left(1-z_{x, B}\right)}\right]^{1 / \alpha} L_{B} Q_{B}(t) \\
Y(t) \equiv \int_{0}^{1} p_{n}(t) Y_{n}(t) d n=\left[\frac{1-\alpha}{q\left(1-z_{x, S}\right)}\right]^{\left(\frac{1-\alpha}{\alpha}\right)} p_{S}^{1 / \alpha}(t) A_{S}^{1 / \alpha} L_{S} Q_{S}(t)+\left[\frac{1-\alpha}{q\left(1-z_{x, B}\right)}\right]^{\left(\frac{1-\alpha}{\alpha}\right)} p_{B}^{1 / \alpha}(t) A_{B}^{1 / \alpha} L_{B} Q_{B}(t) .
\end{gathered}
$$

Equation (13b) shows clearly that: (i) economic growth is driven by the technological-knowledge progress, reflected in the aggregate quality indexes; (ii) the

\footnotetext{
3 The competitive equilibrium threshold $\bar{n}$ arises from profit maximisation by perfectly competitive producers of final goods and by monopolist firms producing intermediate goods, and full-employment equilibrium in factor markets. Thus, $B$ produces final goods $n>\bar{n}$ and $S$ produces final goods $n \leq \bar{n}$.
} 
contribution of $B$ for $Y$ is higher, since, by assumption, $L_{B}>L_{S}$ and $A_{B}>A_{S}$, and, as an endogenous result of the model, $Q_{B}>Q_{S}-$ as will be shown later. ${ }^{4}$

\subsection{Equilibrium R\&D}

The expected current value of the flow of profits to the monopolist producer of $j$, $V(k, j, t),{ }^{5}$ relies on: (i) profits at each $t$ given by (equivalent equation for a producer in $B$ )

$$
\Pi(k, j, t)=L_{S}\left(1-z_{x, S}\right)^{\alpha^{-1}(\alpha-1)}(q-1)\left[\frac{p_{S}(t) A_{S}(1-\alpha)}{q}\right]^{\alpha^{-1}} q^{k(j, t) \alpha^{-1}(1-\alpha)}, \text { for a producer in } S
$$

(ii) the given equilibrium interest rate; and (iii) the expected duration of the flow, which is the expected duration of the successful research's technological-knowledge leadership. Such duration, in turn, depends on $I(k, j, t)$. The resulting expression for $V(k, j, t)$ is:

$$
V(k, j, t)=\frac{\Pi(k, j, t)}{r(t)+I(k, j, t)} .
$$

Hence, the expected income generated by the successful research on rung $k^{\text {th }}$ at time $t, V(k, j, t) r(t)$, equals the difference between profit flow, $\Pi(k, j, t)$, which is paid out as dividends, and the expected capital loss, $V(k, j, t) I(k, j, t)$, which will occur when rung $k^{\text {th }}$ is replaced by a new one. Thus, $r+I$ is the effective discount rate of the successful R\&D.

Under free-entry R\&D equilibrium in each country the expected returns are equal to resources spent:

$$
I(k, j, t) V(k+1, j, t)=\left\{\begin{array}{c}
\left(1-z_{r, S}\right) y(k, j, t), \text { if } 0<j \leq J \text {;i.e., in } S \\
\left(1-z_{r, B}\right) y(k, j, t), \text { if } J<j \leq 1 ; \text { i.e., in } B
\end{array},\right.
$$

The equilibrium can be translated into the path of the technological knowledge. The equilibrium country-specific technological-knowledge growth rate in $S$, for instance, is:

\footnotetext{
${ }^{4}$ Since $S$ is not too backward (i.e., an appropriate taxonomy for $B$ and $S$ would be developed versus developing, rather than developed versus underdeveloped), it is predictable that inter-country differences in prices of final goods are of second order. Moreover, in the context of a monetary union, with single currency and common market, prices of tradable goods tend to be very similar, as well as national inflation rates.

${ }^{5}$ I.e., $V(k, j, t)$ is the market value of the patent or the value of the monopolist firm, owned by consumers.
} 


$$
\hat{Q}_{S}(t)=\{\underbrace{\frac{\beta}{\zeta}\left(\frac{1-z_{x, S}}{1-z_{r, S}}\right)\left(\frac{q-1}{q}\right) L_{S}\left[\frac{p_{S}(t) A_{S}(1-\alpha)}{1-z_{x, S}}\right]^{\alpha^{-1}}-r(t)}_{=I_{S}(t)}\}\left[q^{\alpha^{-1}(1-\alpha)}-1\right] .
$$

In (17), the term in large brackets is the equilibrium country-specific probability of successful R\&D, $I_{S}$, given $r$ and $p_{S}$, which turns out to be independent of $j$ and $k$, due to the removal of scale of technological-knowledge effects.

Equation (17) indicates that subsidies may improve technological knowledge and, through it, the country's level of development. Substituting $p_{S}$ in (17) and $p_{B}$ in the equivalent equation for $B$ by expressions in (12) and equalling $\hat{Q}_{S}(t)$ to $\hat{Q}_{B}(t)$, we find the equilibrium value of $\bar{n}$. After that, the equilibrium levels of $p_{S}$ and $p_{B}$ are also revealed.

The equilibrium aggregate resources devoted to $\mathrm{R} \& \mathrm{D}, R$, at each time $t$, are

$$
R(t) \equiv R_{S}(t)+R_{B}(t)=\int_{0}^{J} y(k, j, t) d j+\int_{J}^{1} y(k, j, t) d j=\zeta \beta^{-1} Q_{S}(t) L_{S} I_{S}(t)+\zeta \beta^{-1} Q_{B}(t) L_{B} I_{B}(t)
$$

Hence, (18) shows that more resources devoted to R\&D in each country (and thus in the union) are needed to offset the greater difficulty of $R \& D$ when the technological knowledge in the country-specific range of intermediate goods rises.

\subsection{Steady state}

Since the aggregate output has constant returns to scale in inputs $Q_{S}$ and $Q_{B}$, and $Y, X, R$ and $C$ are all multiples of $Q_{S}$ and $Q_{B}$, the constant and unique steady-state endogenous growth rate, which through the Euler equation (9) also implies a constant steady-state interest rate, $r^{*}\left(=r_{S}^{*}=r_{B}^{*}\right)$, designed by $g^{*}\left(=g_{S}^{*}=g_{B}^{*}\right)$ is:

$$
g^{*}=\hat{Q}_{S}^{*}=\hat{Q}_{B}^{*}=\hat{Y}^{*}=\hat{X}^{*}=\hat{R}^{*}=\hat{C}^{*}=\hat{c}^{*}=\frac{1}{\theta}\left[\left(1-\tau_{K}\right) r^{*}-\rho\right] \Rightarrow \hat{G}^{*}=\hat{p}_{S}^{*}=\hat{p}_{B}^{*}=\hat{\bar{n}}=0
$$

Thus, $r^{*}$ is obtained by setting the growth rate of consumption in (9) equal to the growth rate of technological knowledge - see (17) - and using the equilibrium levels of $p_{S}$ and $p_{B}$. Then, $g^{*}$ results from plugging $r^{*}$ into the Euler equation (9). 


\section{Government intervention}

Now, we solve numerically the transitional dynamics towards the steady state to illustrate the effect of government intervention on the country-specific technological knowledge. The stability properties of the transitional dynamics towards the steady state are block recursive, in the sense that we can first determine the stability of $G$ and then recursively characterise the behaviour of all the other variables. ${ }^{6}$ Using these results, we analyse whether different fiscal rules may be needed (or not) in order to offset divergences in development among member-countries within a monetary union.

Bearing in mind that $r$ is always unique and using $\hat{Q}_{S}(t)$ and $\hat{Q}_{B}(t)-$ see $(17)-$ we can get the differential equation needed to obtain the path of the technological-knowledge gap between countries, $G$, and then the behaviour of other variables can be characterised:

$$
\begin{aligned}
\hat{G}(t)= & \frac{\beta}{\zeta}\left(\frac{q-1}{q}\right)\left(q^{\alpha^{-1}(1-\alpha)}-1\right)(1-\alpha)^{\alpha^{-1}} \exp (-1)\left\{\left(\frac{1-z_{x, B}}{1-z_{r, B}}\right)\left(\frac{A_{B}}{1-z_{x, B}}\right)^{\alpha^{-1}} L_{B} \times\right. \\
& \left.\times\left[1+\left(G(t) \frac{A_{B}^{\alpha^{-1}} L_{B}}{A_{S}^{\alpha^{-1}} L_{S}}\right)^{-2^{-1}}\right]^{\alpha}-\left(\frac{1-z_{x, S}}{1-z_{r, S}}\right)\left(\frac{A_{S}}{1-z_{x, S}}\right)^{\alpha^{-1}} L_{S}\left[1+\left(G(t) \frac{A_{B}^{\alpha^{-1}} L_{B}}{A_{S}^{\alpha^{-1}} L_{S}}\right)^{2^{-1}}\right]^{\alpha}\right\}
\end{aligned}
$$

From (20) it is possible to give an intuition on how a governmental intervention affects equilibrium. Take for instance an increase in subsidies in $S$. It re-directs R\&D towards designs that improve relatively more its technological knowledge, which increases the relative productivity of its intermediate goods. The development gap between $S$ and $B$ falls, but this intervention creates/increases public deficit in $S$ - see (10a).

Using the fourth-order Runge-Kutta classical numerical method, which solves (20) with suitable precision, the time path of technological-knowledge gap is displayed, bearing in mind the baseline parameter values and labour endowments in Table 1.

\footnotetext{
${ }^{6}$ We solve the model numerically because the differential equation describing the path of $G$ is non-linear and because we want to look at the path of adjustment of some fundamental variables.
} 
We assume that initially $G=1.40, B u S=D=0$ in both countries. For simplification, we assume that there are no taxes and consequently there will be no effects on the budget surplus of one country resulting from changes in the fiscal policy of the other.

Figure 1 sums up the main results, by comparing paths of $(1 / G)$ and $\bar{n}$ under no public intervention (Scenario 0, Sc 0) with the ones resulting from an exogenous increase at $t=0$ of: (Scenario 1, Sc 1) $z_{x, S}$ (to $z_{x, S}=0.1$ ); (Scenario 2, Sc 2) $z_{r, S}$ (to $z_{r, S}=0.1$ ); (Scenario 3, Sc 3) $z_{x, S}$ and $z_{r, S}$ (to $z_{x, S}=z_{r, S}=0.1$ ); and (Scenario 4, Sc 4) $z_{r, B}$ (to $z_{r, B}=0.1$ ). Figure 1 also displays the path of the public deficit to product ratio for $S$ in scenarios 1,2 and 3, and for $B$ in scenario 4. Table 2 compares initial and final steady-state values of the main variables and initial and final values for the deficit to product ratio in all scenarios.

Figure 1 (on separate page at the end of the paper) goes about here

Table 2 (on separate page at the end of the paper) goes about here

Our results clearly indicate that with no governmental intervention (Sc 0) the intercountry technological-knowledge gap, $1 / G$, (and thus the divergence in levels of economic development) would grow significantly. That would cause a decrease in the competitiveness of the small and less developed country, measured by the decrease in $\bar{n}$.

A governmental intervention in $S$, by way of an increase in $z_{x, S}$ and/or $z_{r, S}$ attenuates the inter-country technological-knowledge gap (Sc 1) or even makes it possible for $S$ to reduce this gap (Sc 2 and Sc 3), as Figure 1a shows.

A greater $z_{x, S}$ increases the size of profits that accrue to the producers of intermediate goods in $S$ - see (14) -, while a greater $z_{r, S}$ decreases the cost of R\&D in $S$ - see (16). In this way, an increase in $z_{x, S}$ and/or $z_{r, S}$ boosts the incentives to do R\&D in $S$, thereby increasing the growth rate of its technological knowledge, $Q_{S}$ in (4), which in turn leads to 
a higher $1 / G$. Until the new steady state, such bias increases the supply of intermediate goods in $S$, thereby increasing the number of final goods produced in this country - see (11) and Figure $1 \mathrm{~b}$ - and lowering their relative price at least when compared to Sc 0 - see (12). This path continues towards the constant new steady-state level of the mentioned variables, implying that $1 / G$ is attenuated (Sc 1) or reverted (Sc 2 and Sc 3), but at a decreasing rate until it reaches its new higher steady state level, as depicted in Figure 1a.

As expected, the main adverse effect of the governmental intervention in $S$ is a continuous increase in its public deficit and in the ratio between the public deficit and the GDP. ${ }^{7}$ This increase is relatively under control in Sc 1 , with an indirect subsidy to R\&D through subsidising the production of intermediate goods, but assumes too high values in Sc 2 and 3, from a certain moment of time, as Figure 1c shows.

It is worth noting that the external negative effects of this governmental intervention in the small and less developed country, while in line with those expected (De Grauwe, 2005), are of very limited importance: Table 2 shows slight increases in the price level index in $B$ and in the interest rate within the union when compared to the scenario of nonintervention. In this way, it is possible to argue that financing the deficit running in the small country would have no major negative effects across the union.

Finally, we use Sc 4 to compare the effects arising from the same kind of governmental intervention in $S$ and $B$, allowing us to highlight the importance of economic dimension on external effects of running a (probably) excessive public deficit.

As would be expected, the growth rate of the union, $g$, increases more significantly in the case of a direct subsidy to R\&D given by $B$. This would mean a positive effect for the whole union, however such intervention would lead to an important increase in the technological-knowledge gap and to a significant decrease in competitiveness in $S$.

\footnotetext{
${ }^{7}$ Note that the values of the public deficit would be reduced if taxes were also considered.
} 
The external negative effects of the governmental intervention would be clearly stronger in this case, associated with the creation of an excessive public deficit in $B$, which would be rapidly unsustainable, as the path of the public deficit to product ratio illustrates (Figure 1c). In this case, we observe a significant increase in the interest rate of the union, mainly driven by the need to finance an increasing public deficit, also as an important growth in the price level index of $S$. In this way, it is possible to argue that financing the deficit running in the big country would have major negative effects across the union.

From the results of our model it seems to be possible to consider that:

(i) a governmental intervention subsidising $\mathrm{R} \& \mathrm{D}$ led by a small country in a monetary union induces external negative effects of very little significance, but generates some relevant internal effects, promoting economic convergence within the union;

(ii) a governmental intervention subsidising $R \& D$ led by a big country in a monetary union induces strong external negative effects, raising the interest rate and the price level of the union, at the same time significantly reducing economic and social cohesion;

(iii) temporary differentiation of fiscal rules within the union, allowing less developed and small countries to have more margin for manoeuvre in order to implement temporary (direct and/or indirect) incentives to $\mathrm{R} \& \mathrm{D}$, arises as a valid argument, as it may promote social and economic cohesion with very small costs;

(iv) in this sense, a direct subsidy to $\mathrm{R} \& \mathrm{D}$ works more rapidly, but has stronger negative effects on fiscal discipline, thus its use should be more restricted in temporal terms;

(v) one of the major aspects of the recent SGP reform, namely the consideration of an exceptional character of some public expenses related to the development of innovation and knowledge processes seems to be reasonable, possibly justifying an excessive deficit;

(vi) our results also point to the relevance of some criticisms made to the homogeneity of the European fiscal rules, which do not consider the composition of public expenses or the possibility of financing public investment through the increase of public debt. 


\section{Concluding remarks}

The main purpose of this paper is to discuss one of the main questions raised by the emergence of the EMU, namely the homogeneity of fiscal rules for different countries. In particular, the paper focuses on the possibility for small and less developed countries to run temporarily excessive deficits, in order to improve their economic development and the social and economic cohesion within the union.

To this purpose, we develop a dynamic general-equilibrium growth model with two countries forming a monetary union. Growth is driven by Schumpeterian-R\&D applied to intermediate goods which complement labour in each country. In this context, we analyse the effects of a governmental intervention through subsidising (directly or indirectly) $\mathrm{R} \& \mathrm{D}$ activities and compare them to a situation with no governmental intervention.

An increase in such subsidies in the less developed and small country, $S$, re-directs $\mathrm{R} \& \mathrm{D}$ towards designs that improve the quality of the respective intermediate goods, increasing their productivity. This decreases the domestic relative prices of final goods produced in $S$. Thus, through the price channel, the inter-country technological-knowledge gap is reduced, but at a decreasing rate until it reaches its new steady state. By connecting government intervention with the technological-knowledge progress, we relate government intervention with the path of relative economic development.

Such an intervention would lead to the creation and increase of public deficits. However, should they occur in a small country, their external negative effects would be of very little significance, while inducing some relevant internal effects, namely promoting economic convergence. Conversely, if an excessive deficit were run in the big country, strong external negative effects would occur, raising the interest rate and the price level of the union, and significantly reducing the level of economic and social cohesion.

These results suggest that temporary differentiation of fiscal rules within the union, increasing flexibility for the less developed and small countries, could promote cohesion 
with small costs. In particular, the consideration of an exceptional character of some public expenses connected to the innovation and knowledge processes would be justified. This result goes in line with one of the major aspects of the recent SGP reform.

In future research, we intend to further develop the analysis in order to consider the impact on our results arising from issues such as: (i) the possibility of cheaper R\&D imitation by the less developed country; (ii) the existence of taxation; (iii) the welfare analysis; and (iv) the possibility of other positive external spillovers from fiscal policies.

\section{References}

Acemoglu, D. and Zilibotti, F. (2001) Productivity Differences, Quarterly Journal of Economics, 116, 563-606.

Afonso, O. (2006) Skill-biased Technological Knowledge Without Scale Effects, Applied Economics, 38, 13-21.

Aghion, P. and Howitt, P. (1992) A Model of Growth through Creative Destruction, Econometrica, 60, 323-352.

Alves, R. H. and Afonso, O. (2007) The 'New' Stability and Growth Pact: More Flexible, Less Stupid?, Intereconomics, forthcoming.

Baldwin, R. and Wyplosz, C. (2006) The Economics of the European Union. McGraw Hill, Berkshire.

Brunila, A. (2002) Fiscal Policy: Coordination, Discipline and Stabilization, Bank of Finland, Helsinki, Discussion Paper No 7-2002.

Connolly, M. (2003) The Dual Nature of Trade: Measuring its Impact on Imitation and Growth, Journal of Development Economics, 72, 31-55.

Connolly, M. and Valderrama, D. (2005) A North-South Technological Diffusion: a New Case for Dynamic Gains from Trade, Mimeo, Duke University.

Available at http://www.econ.duke.edu/ connolly/tech.pdf 
Creel, J. (2003) Ranking Fiscal Policy Rules: the Golden Rule of Public Finance versus the Stability and Growth Pact, Documents de Travail de l'OFCE, 2003-04, Observatoire Français des Conjonctures Économiques.

De Grauwe, P. (2005) The Economics of Monetary Integration, Oxford University Press, $6^{\text {th }}$ edition.

European Council (2005) Presidency Conclusions, European Council Brussels. Concl 1, 7619/1/05. Available at http://ue.eu.int/ueDocs/cms_Data/docs/pressData/en/ec/84335.pdf European Council (1997) Resolution on the Stability and Growth Pact, Official Journal of the European Communities, $\mathbf{C 2 3 6 / 1 .}$

Falk, M. (2006) What Drives Business Research and Development (R\&D) Intensity Across Organisation for Economic Co-operation and Development (OECD) Countries?, Applied Economics, 38, 533-547.

Grossman, G. and Helpman, E. (1991) Innovation and Growth in the Global Economy, Cambridge, Massachusetts: MIT Press.

Kortum, S. (1997) Research, Patenting and Technological Change, Econometrica, 65, 1389-1419.

Milbourne, R., Otto, G. and Voss, G. (2003) Public Investment and Economic Growth, Applied Economics, 35, 527-540.

Mills, P. and Quinet, A. (2001) The Case for Spending Rules. Fiscal Rules, Banca d'Italia, 319-330.

Romer, P. (1990) Endogenous technological change, Journal of Political Economy, 98, S71-S102. 
Table 1. Baseline values of exogenous variables and parameters

\begin{tabular}{|c|c|}
\hline Variables & Value \\
\hline$A_{B}$ & 1.40 \\
\hline$A_{S}$ & 1.00 \\
\hline$L_{B}$ & 1.40 \\
\hline
\end{tabular}

\begin{tabular}{|c|c|}
\hline Variables & Value \\
\hline$L_{S}$ & 1.00 \\
\hline$s_{x, m}, s_{r, m}$ & 0.00 \\
\hline$\tau_{w, m}, \tau_{K}$ & 0.00 \\
\hline
\end{tabular}

\begin{tabular}{|c|c|}
\hline Parameters & Value \\
\hline$\beta$ & 1.00 \\
\hline$\zeta$ & 6.00 \\
\hline$\theta$ & 1.05 \\
\hline
\end{tabular}

\begin{tabular}{|c|c|}
\hline Parameters & Value \\
\hline$\rho$ & 0.02 \\
\hline$\alpha$ & 0.70 \\
\hline$q$ & 3.33 \\
\hline
\end{tabular}

Notes: (i) the baseline values are in line with our theoretical assumptions (for instance, $A_{B}>A_{S}$ ), Acemoglu and Zilibotti (2001), Connolly and Valderrama (2005), and to calibrate the union growth rate around $2.5 \%$; (ii) we consider $\bar{a}=0.42=L_{S}$ and this value is normalised to 1 ; (iii) we start with no public intervention.

Table 2. Initial and final steady-state values of the main variables

\begin{tabular}{|c|c|c|c|c|c|c|c|c|}
\hline & $1 / G$ & $\bar{n}$ & $p_{B}$ & $p_{S}$ & $r$ & $g$ & $(B u S / Y)_{B}$ & $(B u S / Y)_{S}$ \\
\hline Initial & 0.714 & 0.360 & 0.678 & 1.016 & 0.046 & 0.024 & 0.000 & 0.000 \\
\hline Sc 0 & 0.578 & 0.336 & 0.661 & 1.066 & 0.046 & 0.025 & 0.000 & 0.000 \\
\hline Sc 1 & 0.654 & 0.350 & 0.671 & 1.036 & 0.047 & 0.026 & 0.000 & -0.028 \\
\hline Sc 2 & 0.773 & 0.369 & 0.685 & 0.998 & 0.049 & 0.028 & 0.000 & -0.101 \\
\hline Sc 3 & 0.877 & 0.384 & 0.699 & 0.971 & 0.051 & 0.029 & 0.000 & -0.130 \\
\hline Sc 4 & 0.431 & 0.304 & 0.640 & 1.143 & 0.063 & 0.041 & -0.184 & 0.000 \\
\hline
\end{tabular}

Figure 1. Transitional dynamics

a. Technological-knowledge gap, $1 / G$

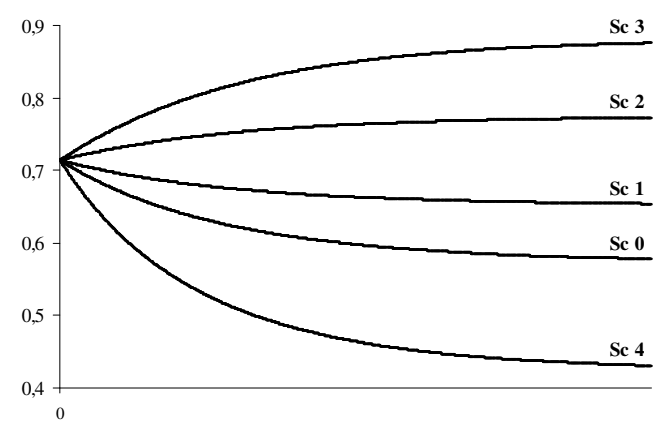

b. Threshold final good, $\bar{n}$

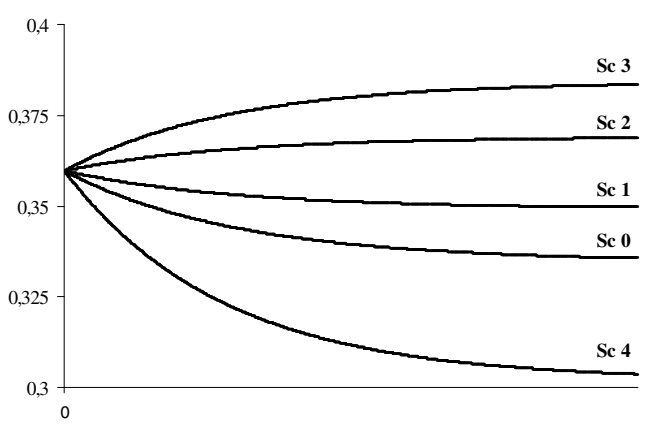

\section{c. Public deficit to GDP ratio, $B u S / Y$}

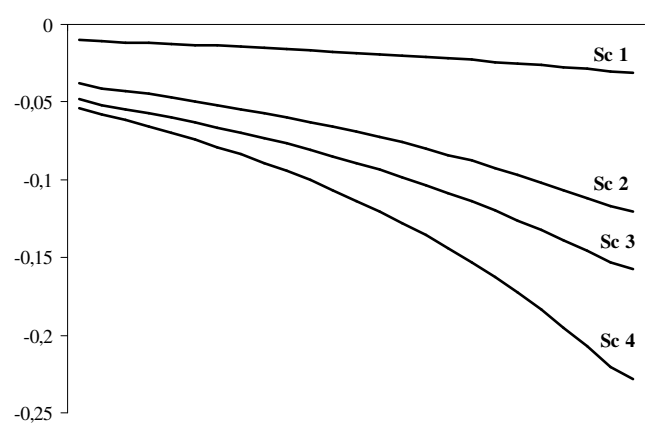

